\title{
THE EFFECT OF DEMOGRAPHIC FACTORS ON FERTILITY BEHAVIOUR IN WESTERN TERAI OF NEPAL
}

\author{
Ram Chandra Acharya*
}

\begin{abstract}
The basic purpose of this research work is to find out the effect of demographic factors on fertility behavior of people in western Terai of Nepal. Trend in fertility is analyzed statistically in detail not only district wise but also for the whole of the western Terai of Nepal on the basis of primary data collect by the researcher. Among different variables, affecting fertility wives' education is found as the most effective variable. It has also been observed that an upward shift in the occupational status, affects the fertility behaviours of couples negatively. Similarly there exists an inverse relationship between income and fertility. Among the couples of different religions Muslims couples have the highest fertility and Hindus have the lowest. Rural respondents have the higher fertility than the urban ones. Among the various castes analyzed it has been deduced that Janajati couples have the lowest mean fertility in the study area. Female respondents use contraceptives more than the male ones.
\end{abstract}

Key words: Demographic factors, Fertility, Surviving, Habitat, Kapilvastu.

\section{BACKGROUND}

In Nepal, the total fertility rate (TFR) is reported as declined from 5.6 in 1991 (CBS, 1995) to 4.6 in 1996 (MOH, 1996). This decline in TFR could be attributed to the rising level of education and contraceptive prevalence. However, TFR of Nepal is still high as compared to some of its neighboring countries in Asia (UN, 1996). Similarly, crude birth rate (CBR) declined from 47.0 per 1,000 in 1961 to 44.0 per 1,000 in 1981 (CBS, 1995). It was recorded 40.7 in 1986 and it increased to 41.6 in 1991 (CBS, 1995).Fertility declined from 4.6 births per woman in 1996 to 3.1 births in the 2006 (NDHS) - a drop of one and half births per woman in the last 10 years. The decline in fertility is more pronounced in the last five years (i.e., between 2001 and 2006). It has declined in every age group over the last ten years, particularly in the older age cohorts. This decrease in fertility in terms of the TFR is unprecedented in Nepal. The TFR has decreased from 4.1 births per woman in 2001 to 3.1 births per woman in 2006 - a 25 percent decrease between the two surveys. Many factors may have contributed to this precipitous decrease in Nepal.

Nepal is said to be overwhelmingly a peasant economy with a population of around 27 million and a per capita GDP of under US $\$ 1$ and seventy-one percent of its population

\footnotetext{
* Mr. Acharya is Associate Professor of Economics, Butwal Multiple Campus, Tribhuvan University, Nepal
} 
lives below the absolute poverty level. Indeed, large segments of these populations are 'hardcore' poor people who barely scratch a living out of fragile, vulnerable ecosystems (Nepal Human Development Report, 2001). The main reason for this is that most of the Nepalese population is dependent on subsistence agriculture 'to produce sufficient food on the family farm using family, (unpaid) kin or reciprocal labour'. The World Bank, in its recent poverty assessment of Nepal in 1998 observed. "Agriculture plays a central role for all", with 86 percent of households cultivating some land, 80 percent having some livestock, and agriculture constituting the main sector of employment for 83 percent of all individuals in the labour forces. As a result of high fertility pressure, producers within this economy find that the fundamental aim of self-sufficiency in staple foods requires more land to be taken for cultivation. But a tightening of the availability of land leads to an increasing pressure on the local environment, forests, fields and pasture. The principal environmental impacts occur in Nepal as a result of individual attempts to achieve adequate levels of subsistence through the desperate exploitation of marginal agricultural lands and forest resources for food and firewood. It can be seen as the key to increasing poverty and a decline in food security. Similarly, the incidence of poverty in Nepal has remained high, largely because of disparities in the ownership of productive resources- both capital and noncapital- and access to them. The agricultural growth has been erratic and has fallen below expectations (Nepal Human Development Report, 2001). This has widened inequalities in income distribution. In socioeconomic context, high fertility persists as a result of complex changes in family power structure, in the patterns of consumption within the family, and in the relations between the generations and between the sexes. More fundamentally, children are net economic assets and a labour pool in order to fulfill the subsistence needs of its members.

In Nepal's demographic profile, there exist remarkable differences in hilly and terai regions. Density of Terai is increasing rapidly. The features of population of our study area are also changing very fast. They are given Table 1.

Table 1: Population Density and Sex Ratio 2001

\begin{tabular}{|l|l|l|l|}
\hline \multirow{2}{*}{ Population features } & \multicolumn{3}{|c|}{ Regions } \\
\cline { 2 - 4 } & Nepal & Western Development Region & WesternTerai \\
\hline Density per sq. Km. & 157 & 155 & 333 \\
Population \% Rural & 86.06 & 88.6 & 89.86 \\
Urban & 13.94 & 11.4 & 1014 \\
Sex Ratio (M/per 100F) & 99.8 & 92.6 & 102.7 \\
\% Increase 1991-2001 & 25.2 & 21.2 & 31.8 \\
\hline
\end{tabular}

Source: Population Monograph of Nepal, Volume I. CBS 2003: 57, 398 
We see that western Terai is denser (i.e. 333 per sq. km.) in comparison to the other regions. The proportion of the women in western Terai is much higher than the proportion of women in other regions. In the same way, population in rural area is higher than the urban area.

\section{Western Terai of Nepal}

The western Terai lies in the Southern part of the Western Development Region. It consists of three districts: Nawalparasi, Rupandehi and Kapilvastu. These districts are located in the Terai region. Geographically, it is located in the central part of the country. The Mahendra Highway crosses through the east to west and Siddhartha Highway (Sunauli-Pokhara) which traverses from south to north while passing through Rupandehi District, connects the two major towns, Siddharthanagar (Bhairahawa) and Butwal, the most active commercial centers in the western Terai.

The number of households, average households size; male - female population, population density and the area of the districts of study area are given in Table 2.

Table 2: Number of Households, Average Household Size, Sex, Area and Population Density of the Study Area

\begin{tabular}{|c|c|c|c|c|c|c|c|c|c|}
\hline 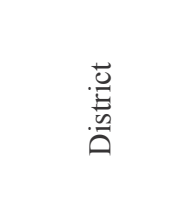 & 吾 & $\frac{0}{\sum^{\pi}}$ & $\begin{array}{l}\frac{0}{\pi} \\
\frac{0}{0} \\
\text { II }\end{array}$ & 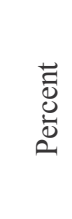 & 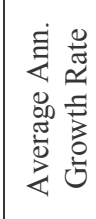 & 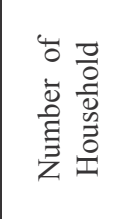 & 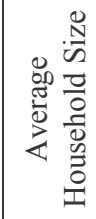 & 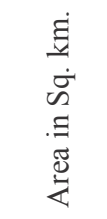 & 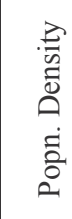 \\
\hline Nawalparasi & 562870 & 278257 & 284613 & 2.43 & 2.55 & 98340 & 5.72 & 2162 & 260 \\
\hline Rupandehi & 708419 & 360773 & 347646 & 3.06 & 3.05 & 117856 & 6.01 & 1360 & 521 \\
\hline Kapilvastu & 481976 & 247875 & 234101 & 2.08 & 2.6 & 72932 & 6.66 & 1738 & 277 \\
\hline Western Terai & 1753265 & 886905 & 886360 & 7.57 & 2.76 & 289128 & 6.06 & 5260 & 333 \\
\hline Nepal & 23151423 & 11563921 & 11587502 & 100 & 2.25 & 4253220 & 5.44 & 147181 & 157 \\
\hline
\end{tabular}

Source: Population Monograph of Nepal Volume 1: 2003 P. 46, 57

In this area, the population of males is 886905 and that of females is 886360 , which is $7.57 \%$ of the total population of the country. The average annual growth rate is 2.76 and total number of households is 289128 . The average household size is 6.06. The total area of western Terai is $5260 \mathrm{sq}$. kms. and population density is $333 \mathrm{sq} . \mathrm{km}$. as shown above in the table.

In the western Terai $53.77 \%$ of the total population is literate. Out of this, $65.2 \%$ are males and $42.1 \%$ are females. Similarly in Nawalparasi, Rupandehi and Kapilvastu literate males are $66 \%, 76.2 \%$ and $53.3 \%$, respectively whereas literate females are 
$40.9 \%, 55.9 \%$ and $29.5 \%$, respectively. It reveals that total literacy in Nawalparasi, Rupandehi and Kapilvastu is 53.3\%,6\% and 41.8\%, respectively. Rupandehi district has higher literacy rate than other two districts (Population Monograph of Nepal Volume 1:2003).

There are 1242 primary schools. Among them, 533 are in Nawalparasi, 454 in Rupandehi and 255 in Kapilvastu. Similarly, the lower secondary schools are 414 in all. Among them, 152 are in Nawalparasi, 186 are in Rupandehi and 76 are in Kapilvastu. In the same way, the total secondary schools in western terai are 265. Among them, 89 are in Nawalparasi, 129 are in Rupandehi and 47 are in Kapilvastu (Department of Education, Nepal, 2008).

When we consider the religious faiths in western Terai, $84.54 \%$ people follow Hinduism in all. Among them, $87.23 \%$ people follow Hinduism in Nawalparasi. But in Rupandehi and Kapilvastu $85.34 \%$ and $81.06 \%$ people follow Hinduism respectively. In western Terai, $4.84 \%$ follow Buddhism in all. Among them $8.18 \%$ are in Nawalparasi, $5.64 \%$ in Rupandehi, $0.68 \%$ in Kapilvastu respectively. The percentage of Muslims on western Terai is $10.24 \%$. In Nawalparasi 3.86\% Muslims live. In Rupandehi and Kapilvastu the percentage of the followers of Islam is $8.69 \%$ and 18 .

\section{OBJECTIVES}

The main objective of this research is to identify demographic factors responsible for a high rate of fertility in the study area.

\section{Review of Literature}

Some important findings on the relationship between fertility and socio-economic, religious and demographic factors have been reviewed in this chapter in certain broad categories for the purpose of the study. In 1956, Davis and Blake "presented a framework which focused on the industrial mechanism in society and listed eleven intermediate variables through which any factors such as biological, social, and psychological or cultural must operate upon individual fertility" (Tuladhar, 1989). The proposed "intermediate variables" are centered around intercourse, conception and gestation. These eleven variables affect positively or negatively the fertility of individuals in a society. These variables are: age into sexual union, permanent celibacy, contraception, sterilization, time between unstable unions, post-widowhood celibacy, foetal mortality from voluntary causes, voluntary abstinence, foetal involuntary mortality, involuntary abstinence and frequency of coitus and inventory sterility.

Age at marriage is regarded as one of the dominant factors of fertility. A woman's total child birth during her fertility period is almost guided by the duration of time she spends with her husband after marriage and also by other social, cultural and economic variables. Marriage age is confirmed as per socio-cultural norms and values. 
An increase in age at marriage will definitely lower down the reproductive period and the births per woman too will definitely be reduced in number. This fact has been proved by most of the studies. It has been found out that an increase in the women's age at marriage contributed to a reduction in fertility. Thus, one of the most important determinants of fertility is the reproductive age, which is associated with age-specific fertility rate. Postponement of age at marriage will certainly lower the number of children ever born to a woman.

Unless age at marriage continues to rise, the use of contraception will be the dominant factor for further reduction in fertility. Post-partum sterility or amenorrhea is another psychological phenomenon which motivates wide-spread practice of breast-feeding for babies for 2 to 3 years in order to lower fertility. One of the studies carried out in Bangladesh by Shahidullah and Chkrobortyl (1993) concluded that lactational infecundability plays the most prominent role as a fertility-reducing factor. So, it is essential to provide more information to women about the low cost and much greater benefits of longer duration breast feeding in order to encourage full and intrusive breast feeding, because the fertility-inhibiting effect of marriage and lactational infecundability are common persisting each other. Different studies conclude that the longer the women breastfeed, the lower is the chance to conceive. This is a natural mechanism for lowering fertility. Bongaarts(1983) demonstrated that 96 percent of the variance in the duration of post partum amenorrhea could be explained by breastfeeding alone. However, he also noted that post-partum amenorrhea phase cannot be lengthened much by lactation beyond two years.

Demographic transition theory states that fertility is high in poor, traditional societies because of high mortality, lack of opportunities for individuals, less advancement and higher economic value of children. These all change with modernization or urban industrialism and individuals, once their viewpoints become reoriented to the change that have taken place, can make use of the new opportunities (Caldwell, 1989).

A study carried out in 2006 entitled "Demographic and Health Survey of Nepal" indicates that there has been an unprecedented decline in fertility from 4.6 births per woman in 1996 to 3.1 births per woman in 2006, a drop of one and a half births per woman in the past ten years. The decline is more pronounced in the five years between 2001 and 2006 (a one child or 24 percent decline) than between 1996 and 2001, with declines observed in every age group over the past ten years, and larger declines seen in the older than younger age cohorts. Fertility is considerably higher in rural (3.3 births per woman) than in urban areas (2.1 births per woman). There are noticeable differentials in fertility among ecological zones and development regions, ranging from a low of 3.0 births per woman in the hills to a high of 4.1 births per woman in the mountains, and from a low of 3.0 births per woman in the central region to a high of 3.5 births per woman in the Mid-and Far-western regions (Demographic and Health Survey of Nepal, 2006). 
Similarly, a seminar paper submitted by Sarker(2006) entitled "The Relationship between Fertility and Socio-Economic Development in Selected States of India 2006" clearly states that fertility decline is not just a by-product of economic growth. It depends on improvement in the specific conditions that are conducive to fertility change and that help parents to realize these goals. The negative relationship between fertility and female work participation rate indicates the requirement of programmes that control the conditions of labour force market. The massage seems to be quite surprising, but it is important to note that variables related to the status of women have a significant influence on fertility.

\section{METHODOLOGY}

In our study we adopted multi-stage sampling to get the ultimate sampling unit. The western Terai consists of three districts such as Nawalparasi, Rupandehi and Kapilvastu. There are thirteen constituencies in all in these districts. A constituency is a political division of the district. There are four constituencies in Nawalparasi, five in Rupandehi and four in Kapilvastu. It consists of Municipalities and Village Development Committee (VDC) in Nepal. The rural sector of western Terai consists of VDCs and there are municipalities in the urban sector of western Terai. Among thirteen constituencies, there are 219 VDCs and 4 municipalities. We have considered all the thirteen constituencies but sampling is not done either at the district level or at the level of constituencies.

At first, 26 VDCs out of 219 VDCs were selected randomly. From the research area, western Terai of Nepal, VDCs were selected in such a way that our sample be representative of the whole population. We have selected only two VDCs from each constituency taking into account the structure of the research field. To give representation to rural and urban population, all the four municipalities were selected to study fertility differentials between rural and urban sector of western terai. A village development committee (VDC) is also a political division of a constituency. It is like a Gram Panchayat of India. A VDC consists of nine wards. Similarly, a municipality is also divided into wards. A ward is a political division of VDC and municipality. Generally one ward represents a village in a VDC and there are wards only in Municipalities. Therefore, we have taken villages from VDCs and wards from Municipalities in our sample.

For the purposed work, a simple random sample (SRS) containing 500 households

was drawn from the selected VDCs using the following formula: $n h=\frac{n}{N} \cdot N h$

where, $\mathrm{nh}=$ sample size for $\mathrm{nth}$ district $; \mathrm{Nh}=$ total number of households of $\mathrm{nth}$ district $\mathrm{n}$ $=$ total sample size (500); $\mathrm{N}=$ total number of households $; \mathrm{h}=$ number of household in each district.

The sample size for each district such as Nawalparasi (170), Rupandehi (204) and Kapilvastu (126) was determined using the above formula. Considering the size of 
the sample, the primary data were collected through survey schedules. Out of 500 households, 58 were selected from urban sector and the rest 442 were from the rural sector.

\section{ANALYSIS OF THE DATA}

The number of children born and surviving, their mean values in different areas, are given in Table 3:

Table 3: Habitat (Rural/Urban) and Number of Children

\begin{tabular}{|l|l|l|l|l|l|}
\hline Urban/Rural & Mean & $\begin{array}{l}\text { Number of } \\
\text { couples }\end{array}$ & $\begin{array}{l}\text { Number of children } \\
\text { born }\end{array}$ & $\begin{array}{l}\text { Number of } \\
\text { surviving }\end{array}$ & Mean \\
\hline Rural & 2.95 & 442 & 1303 & 1245 & 2.82 \\
Urban & 2.62 & 58 & 152 & 147 & 2.53 \\
Total & 2.91 & 500 & 2355 & 1392 & 2.78 \\
\hline
\end{tabular}

It is evident from the sample data collected that 442 couples from rural areas have given birth to 1303 children in all with an average of 2.95 children per couple. The children surviving in this group are 1245 with an average of 2.82 children per couple. Similarly, 58 couples from urban area have given birth to 152 children with an average of 2.62 children per couple. The children surviving in this area are 152 with an average of 2.53 children per couple.

$17 \%$ respectively and $0.38 \%$ of the people in western Terai follow other religions (CBS, District Profile-2006). Out of 500 couples 314 couples are Hindus; 51 are Buddhists; 119 are Muslims; and 16 are from other religions. The total number of children born to them is $831,139,440$ and 45 , respectively, with an average of 2.65 for Hindus, 2.73 for Buddhists, 3.70 for Muslims, and 2.81 for others the average number of surviving children for Hindus is 786, for Buddhists 132, for Muslims 431 and for other religions it is only 43. The mean number of children surviving for Hindus, Buddhists, Muslims and others are $2.50,2.59,3.62$ and 2.62 respectively.

Caste-wise population in the study area has been divided into four categories Brahmins and Chhetris, Janjatis, Dalits and Muslims. Among them, 161 couples were from Brahmins and Chhetris caste, 142 from Janjatis caste, 78 from Dalits caste and 119 from Muslims caste.

The total number of children born among Brahmins and Chhetris caste is 427; for Janajati, Dalit and Muslims it is 374, 214 and 440 respectively. The number of children born for the four castes is 2.65, 2.63, 2.74 and 3.70 respectively. The number of children surviving for the four castes is 397, 363, 202 and 431 respectively and their mean fertility is 2.47, 2.552 .59 and 3.62 respectively. The Muslim couples are bearing the highest number of children in comparison to other castes. 
Respondents are divided into four groups according to their income. The lowest income group is NRs O-4000 and the highest income group is above NRs 8000 per month. This income group is divided keeping in view the prevalent income level of the respondents. The monthly income of 99 couples is Rs 4000 .There are 242 couples in the income group Rs 4001- 8000 and only 92 couples are in the income group Rs 8000 and above. The mean number of children born for the four groups is 3.16, 3.00, 2.76 and 2.51 respectively. Similarly, the number of children surviving in each category is $300,623,180$ and 219 and their mean is $3.03,2.86,2.69$ and 2.38 respectively from the first to the last group. It implies that lower income level people have high birth rate and high income level people have lower birth rate.

To find out the effect of occupation, respondents are divided in three categories on the basis of husbands' occupation. We have considered three categories of occupationAgriculture, Labour, and Clerk and Professionals. Out of 486 husbands, 304 are in Agriculture category, 130 are in labourers' category and 52 are Clerk and Professionals. Out of 500 couples, 14 husbands are dead. In our sample a large number of couples, (304) are dependent on agriculture. Their mean is 3.00 but the number of children surviving is 2.91, which is the highest in comparison to other occupations. There are 130 couples in labour category and 52 are clerks and professionals. The number of children they bore is 378 and 125 and their mean fertility is 2.91 and 2.40 respectively. The surviving number of children is 352 and 116 respectively and their mean is 2.71 and 2.23. Clerks and Professionals have the lowest mean number of children surviving.

To assess the effect of education, husbands' education is divided in four categories illiterate, primary to below SLC; SLC and Intermediate and graduates and above. Out of 486 respondents 125 husbands are illiterate; 176 husbands are from primary to below SLC; 116 are SLC and Intermediate and 69 are in the category of graduates and above. The number of children born is found to be 444, 512, 297 and 162, respectively. The mean number of children born in each category is 3.55, 2.91, 2.56 and 2.35 respectively. The number of children surviving in each category is 427, 493, 281 and 153. Their respective means are $3.42,2.80,2.42$ and 2.22. It may be observed from the sample data that illiterate have the highest child bearing rate and lowest survival rate and 'Graduates and above' have the lowest child bearing rate and highest survival rate.

In the same way wives' education level is also divided into four categories. Among 500 wives, 179 are illiterate, 195 are in 'Primary to below SLC' category, 105 are SLC and Intermediate and 21 are Graduates and above. Analyzing the facts we can conclude that illiterate group has the highest child bearing rate and the lowest rate of surviving. The 'Graduates and above' group has the lowest bearing rate and highest survival rate. By and large, we can conclude that the higher the level of education, the lower is the fertility and the lower the level of education the higher is the fertility. 
Current age of wives in the sample has been divided into three groups - 15 - 24, 25-34 \& 35-49 according to their present age. There are 31 wives between 15-24 age group, 198 are between 25-35 age group and 271 are between 35-49 age group. From the sample data it is clear that increase in the age of wives means that the number of children also increases. Owing to the simultaneous increase in the duration of married life. The first age group, 15-24, has 54 children and its mean is 1.74 . The number of children surviving is 51 and its mean is 1.65 . The second group, 25-34, has 557 children and its mean is 2.81. The number of children surviving is 529 , its mean is 2.67 whereas the last group, 35 to 49 , has 844 children; its mean is 3.11 . The number of surviving children is 812 and its mean is 3.00. It is assumed that there exists a relationship between age at marriage of wives and the number of children born and surviving. To analyze this, the age at marriage of wives is divided in three groups - 0-15, 15-19, and 20 and above. In our sample data there are 283 children in the age group, $0-14$, and the mean number of children born is 3.14 and the mean survival rate is 3.00 .

We find that the number of couples who desired to give birth up to 2 children in rural area is 70 and in urban area, it is 30 . Similarly, three children are desired by 182 couples in rural area and by 19 couples in urban area. Four children are desired by 159 couples in rural and 9 couples in urban area. Similarly, thirty one couples of rural area desired either 5 or more children. On the basis of the above table we can say that the couples in rural area desire to give birth to more children than the couples in urban area.

In order to find out the effect of habitat and desired sex ratio on fertility, respondents are divided into urban and rural ones and the sex ratio of desired number of children is also determined. In the sample distribution, it is found that sixty nine rural and thirty urban couples desire only one son and one daughter. In the same way, rural couples (179) desire to have two sons and one daughter whereas urban couples (19) desire to have two sons and one daughter; one hundred ninety one rural and nine urban couples desired a different composition of sex ratio. From this we can say that the preference for son is higher than the daughter in both areas.

It is clear that 85 wives' in rural area and 5 wives' in urban area got married below 14 years, 284 in rural and 35 urban wives got married between the age of $15-19$ whereas 73 rural and 18 urban wives' got married at 20 years or thereafter.

Four different castes - Brahmins and Chhetris, Janajatis, Dalits and Muslims - have been considered to assess the number of children they like to bear. In the study, it is found that 35 Brahmins and Chhetris couples desired to give birth to 2 children. Similarly, 37 couples of Janajatis, 19 of Dalits and 9 of Muslims desired the same number of children. But, 77 couples of Brahmins and Chhetris castes, 56 couples of Janjatis caste, 28 Dalit couples and 9 Muslim couples desired to give birth to 3 children. It has been observed that 47 couples of Brahmins and Chhetris caste, 46 couples of Janajati, 30 Dalits and 45 Muslims couples desired to give birth to 4 children. Similarly, 2 couples of Brahmins 
and Chhetris, 3 couples of Janjatis, 1 couple of Dalits and 25 Muslim couples desired to give birth to 5 and above children. . In this way, Muslim couples desire to give birth to more children in comparison to the couples of other castes.

An attempt was made to find out the desired number of sons and daughters by couples. It was observed that one son and one daughter were preferred by 34, 37, 19 and 9 couples of Brahmin and Chhetris, Janajati, Dalit and Muslim couples respectively. Similarly, one son and two daughters were desired by 4 couples of Brahmins and Chhetris and 1 couple of Muslim. Furthermore, two sons and one daughter were desired by 75 Brahmins and Chhetris couples, 56 Janjatis couples, 28 Dalits couples and 39 Muslim couples.

It is necessary to study birth interval or spacing between two births in order to know fertility trend of any country or community mainly because birth interval is an important indicator of fertility behavior of the couples. The facts in this regard are presented from the time of effective marriage to the last birth in Table 4.

Table 4: Couples by Birth Interval

\begin{tabular}{|c|c|c|c|c|c|c|c|c|}
\hline & 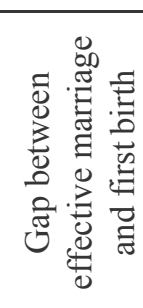 & 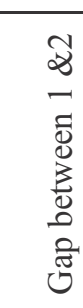 & 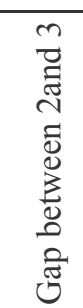 & 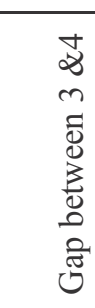 & $\begin{array}{l}2 \\
\infty \\
+ \\
0 \\
0 \\
0 \\
0 \\
0 \\
0 \\
0 \\
0\end{array}$ & $\begin{array}{l}0 \\
0 \\
n \\
0 \\
0 \\
D_{0}^{0} \\
0 \\
0 \\
0\end{array}$ & 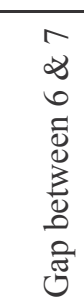 & 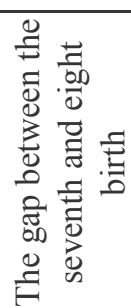 \\
\hline Valid & 497 & 447 & 301 & 135 & 49 & 18 & 7 & 1 \\
\hline NA & 3 & 53 & 199 & 365 & 451 & 482 & 493 & 499 \\
\hline Mean & 1.64 & 2.95 & 3.15 & 3.15 & 3.29 & 2.56 & 2.43 & 2.00 \\
\hline Median & 1.00 & 3.00 & 3.00 & 3.00 & 3.00 & 2.00 & 2.00 & 2.00 \\
\hline
\end{tabular}

The mean gap between effective marriage and first birth is 1.64 years but the median year is only 1 . The mean gap between $4^{\text {th }}$ and $5^{\text {th }}$ birth is 3.29 which is the maximum. It then declines and for the $7^{\text {th }}$ and $8^{\text {th }}$ birth it becomes only 2 years. Similarly, the median gap in years increases and after $5^{\text {th }}$ birth it declines and becomes steady. In the sample there are $344(68.8 \%)$ couples who give birth to a child within a year of their marriage. Similarly, $75(15.0 \%)$ couples gave birth to a child between 1 to 2 years after their marriage; 27 (5.4\%) couples bear a child between 2 to 3 years, and only $13(2.6 \%)$ couples gave birth after 3 to 4 years of gap. And 38 (7.6\%) couples gave birth to a child 4 years after their marriage. Thus, we find that more than $68.8 \%$ gave birth within a year of their marriage. It is therefore; clear that reasonable birth spacing does not exists in the study area (Western Terai of Nepal). 
It may also be observed that 158 (31.6\%) couples gave birth to their second child within 2 years after first birth. Similarly, 117 (23.4\%) couples gave birth within 2 to 3 years, 59 $(11.8 \%)$ couples gave birth after 3 to 4 years, and 76 (15.2\%) couples gave birth to the second child after 4 years of the first birth and more than $38 \%$ couples gave birth to their second child within 2 years after the first child.

For the gap maintained by the couples for their third child we have found from the data that that $18.8 \%$ couples gave birth to their third child within a year after the second birth; $20.4 \%$ couples gave birth within 2 years; $9.2 \%$ couples gave birth within 2 to 3 years, whereas $10.6 \%$ couples gave birth after 4 years. But, $60.2 \%$ couples gave third birth within three years of the second birth.

In addition to this we find that $27 \%$ couples gave birth to the fourth child in which $10.0 \%$ couples gave birth to fourth child within 2 years after the third birth; $7.0 \%$ couples give birth within 2 to 3 years, 2.8\% couples gave birth within 3 to 4 years and $6.4 \%$ couples give birth to fourth child four years after the third birth. In the sample data, 49 couples gave birth to the fifth child. Among them 3.2\% couples gave birth to fifth child within an interval of 1 to 2 years; $2.4 \%$ couples gave birth to fifth child within an interval of 2 to 3 years and only $1.8 \%$ couples gave birth to fifth child within an interval of 4 years.

Out of 500 couples, $3.6 \%$ couples gave birth to the sixth child. Out of these $3.6 \%$ couples, $2.0 \%$ couples gave birth to sixth child within an interval of 1 to 2 years; $1.4 \%$ couples gave birth to sixth child within an interval of 2 to 3 years and only one $(0.2 \%)$ couple gave birth to the sixth child within an interval of 4 years. Only $1.4 \%$ couples gave birth to seventh child. Among them, $1 \%$ couples gave birth to the seventh child within an interval of 1 to 2 years; two $(0.4 \%)$ couples gave birth to the seventh child within an interval of 2 to 4 years and only one $(0.2 \%)$ couple gave birth to the eighth child within an interval of 2 years.

From the birth interval Table 4, it can be confirmed that the couples of the study area tend to give birth to many children ignoring the value and importance of birth interval. However, most of the couples gave birth to a child even before their first marriage anniversary. Some of the couples have maintained only one or two years of interval. Thus, it may be concluded that the people of the study area are unaware of the importance of the child spacing and effective use of contraceptives for the development and growth of children and mother's health.

\section{CONCLUSIONS}

Western Terai is multiracial and multilingual region. Majority of the total population follows Hinduism whereas minorities of people follow Islam, Buddhism, Christianity and so forth. Although Nepali is official language, some castes/ethnic groups of this area speak Bhojpuri, Tharu and Newari languages as their mother tongue. 
Education creates awareness about the socio-economic problems. It enhances occupational status, implants ideas about the appropriate age for marriage, reduces desire only for son rather than daughter; keeps them busy performing activities for their personal career development and social development. The educational development in this region is not satisfactory. As a result, people do not have right attitude towards gender. They think it is extremely necessary to give birth to a son. Specially, they like to have a son because they think if they don't give birth to a son, they don't reach to heaven after their death. It is also believed that a son can continue ancestral family traditions and customs. Such convictions lead them to increase the fertility size. Similarly, the couples think that the newly born child struggles himself or herself in some menial jobs to fulfill the appetite because he/she will have one mouth but two hands. Such a conviction leads them to bear a number of children.

In Nepalese society where the males are allowed to have more than one wife, they give birth to many children. This practice is conducive to population growth. Some religions, like Islam does not have any restriction on the number of marriages. Therefore, the people belonging to this religious group get married to more than one wife and the number of children of these people is more than the people who belong to other religious groups. In the same way, women who are confined only to carry out household jobs are considered suitable for producing children. Those women who can produce larger number of children are held in high esteem. Certainly, the fertility is very high in such societies as compared with the societies where the women are expected to participate in all walks of life with men or where the women are equally treated like men

Fertility is extremely influenced by economic conditions of the family, education of couples, occupation, sources of income, marriage age, social customs, traditions, culture and so forth. Population growth rate is high in western terai although the mortality rate has sharply declined due to the increased health centers, medical and other welfare facilities.

\section{References}

Bongaarts, R.and Potter, R.G. (1983). Fertility Biology and Behaviour An Analysis of The Proximate Determinants - Academic Press New York,

Caldwell, J.C., Gajnayake, I., Caldwell B. and Caldwell, P. (1989). Is Marriage Delay a Multiphasic Responses to Pressures for Fertility Decline? -The Case of Sri Lanka - Journal of Marriage and Family, 1989, 51: 337-351

Central Bureo of Statistics (1995). District Profile, Nepal,

Central Bureau of Statistics Nepal (2006). Demographic and Health Survey, p.xxiii.

Debarati, S.(2006). The Relationship between Fertility and Socio-economic Development in selected states of India - International institute for Population Science, Deonar, Mumbai. 
Central Bureau of Statics (2003). Population Monograph of Nepal Vol. 1:37- 94.

Ministry of Health Survey (1996). Ministry of Health, CBS, HMG of Nepal: P.86, 302

Nepal Human Development Report (2001).

Shahidullah, Md. and Chkrobortyl, N. (1993). Factors Affecting the Use of Contraceptives in Bangladesh: A Multivariate Analysis - Asia-Pacific Population Journal, 8( 3): 28-32

Tuladhar, J. M. (1989). The Persistence of high fertility in Nepal, Inter India Publications D. 17 Raja Garden exten - New Delhi P. 39

United Nations (1961). The Mysore Population Studies: A Co-operative project of the U.N. and the Government of India - Economic \& Social Affairs, 83-85 